\title{
TARIFAS DE IMPORTAÇÃO E EVASÃO FISCAL NO BRASIL*
}

\author{
HONORIO Kume ${ }^{\dagger}$ \\ GUIDA PIANI ${ }^{\ddagger}$ \\ Pedro Miranda ${ }^{\S}$
}

\begin{abstract}
Resumo
A evasão de impostos, sobretudo por meio de subfaturamento das importações, sempre foi motivo de preocupação da administração aduaneira. Além da redução de receita tributária, a sonegação impõe perdas de competitividade aos importadores que assumem todos os encargos tributários, e reduz o grau de proteção à produção doméstica. O objetivo deste trabalho é verificar empiricamente a relação entre os níveis de tarifa aduaneira e o subfaturamento das importações no Brasil, e se este resultado é influenciado pelas características específicas de determinados bens (produtos diferenciados), bem como pela presença de produtos similares com tarifas menores. Entre outros fatos, os resultados apontam que o aumento de um ponto de percentagem na alíquota da tarifa implica uma elevação de 3,1\% no nível de sonegação. Na comparação entre bens diferenciados e homogêneos, as estimativas indicam uma elasticidade maior para os primeiros.
\end{abstract}

Palavras-chave: tarifa de importação; evasão; arrecadação

\begin{abstract}
Tax evasion in Brazilian imports has been an issue of concern for the customs authorities. This problem is addressed here using the theoretical approach of defining evasion as the difference between the value of exports of other countries to country-regionBrazil and value of imports reported by country-regionplaceBrazil. This makes it possible to quantify the effects of high import tariff rates on tax evasion due mainly to underreporting of value. The main empirical result of the paper is that a one-percentage-point increase in the tariff rate implies a $3.1 \%$ increase in evasion. Furthermore, we identify an also robust elasticity of evasion of $3.2 \%$ for differentiated products in contrast with a lower value of $2.2 \%$ for homogeneous products.
\end{abstract}

Keywords: tariffs; tax evasion; tax collection

\footnotetext{
* Os autores agradem os comentários e as sugestões recebidos de Erly Cardoso Teixeira, dos participantes do seminário realizado pela Dimac do IPEA e de um parecerista anônimo. Agradecem também a Milton Pina Júnior pelo fornecimento dos dados.

${ }^{\dagger}$ IPEA e UERJ. E-mail: honorio.kume@ipea.gov.br.

‡ IPEA. E-mail: guida.piani@ipea.gov.br.

§ IPEA. E-mail: pedro.miranda@ipea.gov.br.
} 


\section{Introdução}

A evasão de impostos, principalmente por meio de subfaturamento das importações, sempre foi motivo de grande preocupação para a administração aduaneira. Além da redução de receita tributária, a sonegação impõe perdas de competitividade aos importadores que assumem integralmente os encargos tributários e, o que é mais importante, reduz o grau de proteção conferida pela estrutura tarifária à produção doméstica.

Nos últimos tempos, a imprensa brasileira tem dado destaque às operações policiais que combatem esse tipo de fraude fiscal praticada por empresas que registram um valor inferior ao preço efetivo de transação. Como o verdadeiro preço não é uma informação disponível, à exceção dos produtos cotados em bolsas de mercadoria ou em publicações especializadas, a administração aduaneira enfrenta muitas dificuldades para detectar essa prática.

O governo brasileiro tem recorrido a outros instrumentos para combater o subfaturamento das importações. Na aplicação de direitos antidumping, por exemplo, tem utilizado de forma crescente alíquotas específicas (ad rem) um valor monetário fixo por unidade de produto. Em 2002, das 49 medidas antidumping aplicadas, apenas duas eram baseadas em direitos específicos (DECOM-SECEX, 2003). Em 2008, das 57 medidas em vigor, somente 14 eram do tipo ad valorem ${ }^{1}$ (DECOM-SECEX, 2008). Neste mesmo ano, o governo implementou a Lei $n^{\circ} 11.727$, de 23/07/2008, que permite ao Poder Executivo impor um imposto de importação de no máximo $\mathrm{R} \$ 15$ por quilograma ou unidade de produto. ${ }^{2}$

A princípio, quanto maior a tarifa aduaneira, maior deverá ser o valor subfaturado das importações, devido à expectativa de um ganho mais elevado com a evasão fiscal. No entanto, nos modelos teóricos esta relação é ambígua, ou depende de determinadas hipóteses. ${ }^{3}$

No trabalho pioneiro de Allingham \& Sandmo (1972), o contribuinte escolhe que parcela da renda será declarada ao fisco para fins de tributação do imposto de renda, considerando o ganho com a sonegação e a perda decorrente da multa proporcional à renda evadida. ${ }^{4}$ Uma maior alíquota do imposto provoca dois efeitos com sinais contrários: de um lado, eleva o ganho da subdeclaração da renda, incentivando a evasão (efeito-substituição); de outro, diminui a renda líquida do contribuinte, induzindo-o a assumir riscos menores (efeito-renda). Portanto, o impacto de um aumento de imposto sobre a evasão fiscal depende do resultado líquido destes dois efeitos.

Yitzhaki (1974) mostra que se a multa por omissão de renda incide sobre o montante do imposto sonegado, como ocorre nos Estados Unidos, o aumento da alíquota do imposto afeta igualmente as duas situações possíveis, eliminando o efeito-preço. Assim, a ambiguidade desaparece e a relação entre alíquota e evasão fiscal torna-se negativa.

Sandmo (2005) reconhece que um bom modelo não deve comportar ambiguidades, mas considera o resultado de Yitzhaki (1974) contrário à percepção usual de que uma alíquota maior do imposto é favorável à sonegação e su-

\footnotetext{
${ }^{1}$ Uma tarifa é ad valorem quando a alíquota corresponde a um percentual sobre o preço do produto importado, ou seja, o montante do tributo varia com o preço.

${ }^{2} \mathrm{~A}$ aplicação desse instrumento ainda depende da sua regulamentação.

${ }^{3}$ Uma resenha dos modelos teóricos pode ser vista em Siqueira \& Ramos (2005).

${ }^{4}$ A descoberta da omissão tem uma probabilidade fixa e é exógena.
} 
gere uma extensão do modelo para incorporar outros fatores, como o impacto sobre a oferta de trabalho.

Mishra et al. (2007) e Yang (2008) adaptaram o modelo básico e eliminaram a incerteza quanto aos efeitos possíveis. Dados o valor das importações e a tarifa, a firma escolherá que fração das importações será omitida às autoridades aduaneiras, de modo que o ganho adicional com o imposto sonegado seja igual ao custo marginal desta ação, que, por sua vez, depende do próprio valor não declarado e da eficiência do controle aduaneiro. Supondo que a administração aduaneira fiscaliza com mais atenção as importações de maior volume e tarifas elevadas, o custo marginal é crescente. Desta forma, se a tarifa aumenta, o ganho com a sonegação se eleva e o importador terá estímulo para omitir uma parcela maior das importações.

Quanto aos trabalhos empíricos, Bhagwatti (1964) foi o primeiro a analisar essa associação e introduziu a clássica medida de subfaturamento das importações, calculada pela diferença entre o valor das exportações registrado nos países de procedência da mercadoria e o valor declarado no país importador. No período recente, a partir do estudo de Fisman \& Wei (2004), o tema passou a merecer destaque na literatura, sendo seguido pelos estudos de Mishra et al. (2007) e Javorcik \& Narciso (2008).

O objetivo deste trabalho é verificar empiricamente a relação entre os níveis de tarifa aduaneira e o subfaturamento das importações no Brasil. Analisase se tal resultado é influenciado pelas características específicas de determinados bens, que tornariam mais difícil a conferência de preços (produtos diferenciados), bem como pela presença de produtos similares com tarifas menores, o que poderia induzir a uma mudança na classificação do produto para que o importador se beneficiasse de uma menor tributação.

Por último, deve-se destacar que este trabalho foi elaborado basicamente no primeiro semestre de 2008, mas, por um lapso de nossa parte, somente no final de janeiro de 2011 tomamos conhecimento do artigo de Sousa et al. (2008) que trata do mesmo tema aqui analisado. Apesar de ambos terem se baseado no artigo pioneiro de Fisman \& Wei (2004) e apresentarem resultados qualitativos similares, há diferenças importantes nos procedimentos metodológicos. Sousa et al. (2008) analisam as importações brasileiras provenientes dos Estados Unidos, no período 1998-2003, utilizando uma estimação em painel com tarifas legais e incluem três variáveis adicionais (amplitude tarifária, dispersão tarifária e participação percentual nas exportações). Neste trabalho, utiliza-se uma amostra de 96 países exportadores para o Brasil em 2003, as tarifas efetivamente pagas e uma outra variável que identifica o grau de diferenciação dos produtos.

Além desta breve introdução, o trabalho está dividido em quatro seções. Na seção 2, será feita uma resenha dos principais trabalhos disponíveis na literatura. Em seguida, na seção 3, serão descritos os procedimentos para o registro das exportações e importações, as medidas do subfaturamento das importações e as demais variáveis que serão incluídas nas equações a serem estimadas, assim como as fontes dos dados. Na seção 4, serão apresentados os resultados empíricos. Na seção 5 serão resumidas as principais conclusões do estudo. 


\section{Resenha da literatura}

Nesta seção, será apresentado um resumo dos principais trabalhos que tratam do tema da evasão fiscal nas importações.

\subsection{Bhagwatti (1964)}

Esse autor mediu o subfaturamento das importações na Turquia pela diferença entre o valor declarado das exportações free on board (FOB) pelos principais parceiros comerciais - Alemanha, Estados Unidos, França, Holanda e Itália - e o valor das importações cost, insurance and freight (CIF) procedentes destes mesmos países registrado pela Turquia, por setor da Classificação Uniforme de Comércio Internacional (CUCI), nos anos de 1960 e 1961.

Os resultados mostraram diferenças substanciais em seis setores: derivados de petróleo, produtos químicos, artigos manufaturados, equipamentos de transporte e máquinas e manufaturados diversos. Apenas em derivados de petróleo foi possível constatar que as divergências decorriam de erros na designação da fonte exportadora.

Nos demais setores, Bhagwati conclui que havia fortes evidências de que o subfaturamento das importações estava associado ao nível das tarifas, que à época apresentavam alíquotas superiores a 30\%.

\subsection{Fisman \& Wei (2004)}

Esse trabalho, que foi responsável pela retomada do tema, quantifica os efeitos dos impostos incidentes na importação (tarifa aduaneira e imposto sobre o valor adicionado) sobre a evasão fiscal, examinando a relação na China entre a estrutura tarifária e a diferença entre as exportações registradas na classificação do Sistema Harmonizado a seis dígitos (SH6) por Hong Kong com destino a outras regiões da China e as importações declaradas pela China continental provenientes de Hong Kong em 1998. Os resultados obtidos sugerem que uma elevação de um ponto de porcentagem na tarifa está associada com o aumento de 3\% no subfaturamento das importações.

O estudo distingue três diferentes aspectos de evasão tarifária: o subfaturamento do valor unitário, a redução das quantidades taxáveis e a classificação de produtos com tarifas mais elevadas como produtos sujeitos a tarifas menores. As estimativas indicam fortes evidências de classificação indevida e evidência limitada de subfaturamento de valor unitário. Não obstante, não se encontram evidências de redução nas quantidades totais declaradas pelo importador.

Os resultados obtidos são robustos quando controlados pela participação das importações isentas de cada bem e, no caso da estimação por primeira diferença, eliminados os efeitos das características específicas dos produtos.

Finalmente, quando se analisa o efeito marginal da tarifa sobre o subfaturamento das importações, os resultados indicam que para as tarifas superiores a $34 \%$ a evasão aumenta consideravelmente e torna-se estatisticamente significativa. Este padrão de não linearidade é consistente com a existência de um custo fixo na ação de evasão de modo que não há incentivos para esta prática para tarifas menores que este percentual. Alternativamente, também é compatível com a probabilidade de que a descoberta da evasão seja invariante à 
tarifa, de modo que o benefício da evasão aumenta mais rapidamente que o custo, à medida que as tarifas se elevam.

No entanto, surpreendentemente, o subfaturamento cai quando a tarifa é maior que $42 \%$. Uma explicação possível para este resultado é que as autoridades aduaneiras avaliam com mais atenção os produtos com tarifas elevadas elevando os riscos da evasão fiscal.

\subsection{Mishra et al. (2007)}

Os autores examinam o efeito das reduções tarifárias aplicadas na Índia, no período compreendido entre 1987 e 2003, sobre o subfaturamento das importações. Este trabalho se distingue do anterior por apresentar dados em painel, o que permite eliminar as influências das características específicas dos países e dos produtos, ambas invariantes no tempo, e dos efeitos comuns em cada ano. É incluída uma medida de capacidade da administração aduaneira do governo indiano com o objetivo de mostrar como a qualidade da fiscalização afeta a sensibilidade da evasão aos níveis tarifários.

São duas as principais conclusões. Primeiro, o impacto das tarifas sobre a evasão é robusto e significativo, embora relativamente pequeno em magnitude: um aumento de um ponto de porcentagem da tarifa implica um crescimento de $0,1 \%$ da evasão. Segundo, os autores encontram uma forte evidência de que a elasticidade da evasão é afetada por características dos produtos que potencialmente capturam a eficácia da vigilância. Para produtos diferenciados ${ }^{5}$ e para os que apresentam uma alta variância de valor unitário, a elasticidade da evasão encontrada é substancialmente mais elevada.

Em outras palavras, um aumento da tarifa leva a uma evasão maior, quanto mais difícil for para os fiscais aduaneiros discernir o valor verdadeiro do produto.

\subsection{Javorcik \& Narciso (2008)}

Esses autores analisaram a relação entre a diferença dos valores exportados registrados na Alemanha e as importações provenientes deste país declaradas em dez países da Europa Oriental nos anos de 1992 a 2003, por produto SH6. A Alemanha foi escolhida por ser o principal exportador para estes países, e a opção por um único fornecedor teve como preocupação garantir a consistência dos dados.

A relação entre a diferença registrada no comércio e a tarifa legal é positiva e significativa ao nível de $1 \%$ para oito países, com os coeficientes menores de 0,8 (Hungria) e 0,9 (Bulgária) e os maiores de 3,2 (Rússia) e 4,4 (Ucrânia). Estes resultados são consistentes com os níveis de corrupção no serviço aduaneiro, conforme pesquisa efetuada pelo Banco Mundial e pelo Banco de Reconstrução e Desenvolvimento Europeu.

As estimativas em painel com a classificação dos produtos em diferenciados e homogêneos, segundo a definição de Rauch (1999), mostram que um aumento de um ponto de porcentagem na tarifa eleva a diferença nos registros de comércio em $0,6 \%$ nos produtos homogêneos e $2,1 \%$ nos produtos diferenciados.

\footnotetext{
${ }^{5}$ Os autores creditam a grande diferença da elasticidade estimada por Fisman \& Wei (2004) para a China à predominância de produtos diferenciados que compõem a amostra.
} 
Por último, ao analisar os canais pelos quais essa diferença é gerada, os resultados assinalaram como o mais importante a subcotação dos preços em bens diferenciados.

\section{Procedimentos aduaneiros, metodologia e fonte dos dados}

\subsection{Procedimentos para declaração das exportações e das importações}

Para facilitar o entendimento das fontes de divergências entre o valor de exportação registrado no país de procedência e o valor de importação declarado pelo Brasil, na Figura 1 apresentam-se de forma simplificada os procedimentos e os documentos exigidos pelas administrações aduaneiras que geram estas informações.

Após a chegada da mercadoria do exterior e de posse dos documentos que comprovam a propriedade dos bens, a firma importadora deve efetuar o despacho aduaneiro para obter a liberação da mercadoria (desembaraço aduaneiro). Nesse momento, a Secretaria da Receita Federal do Ministério da Fazenda (SRF/MF) confere a veracidade das informações declaradas pelo importador, com base nos documentos apresentados.

Em geral, o despacho de importação é processado através da Declaração de Importação (DI), registrada no Sistema Integrado de Comércio Exterior (Siscomex), que deve ser preenchida com base nos seguintes documentos: a fatura comercial (equivalente à nota fiscal) - emitida pelo exportador -, o conhecimento de carga (bill of lading) e o romaneio de carga (packing list) - fornecidos pela empresa responsável pelo transporte da mercadoria. Em alguns casos, outros documentos podem ser exigidos quando especificados em legislação própria ou em decorrência de acordos comerciais, tais como o atestado sanitário - que garante o cumprimento dos requisitos de saúde animal - e o certificado de origem - que confirma o país onde o bem foi produzido (SRF/MF, 2008).

Para avaliar se o valor importado foi declarado corretamente, a SRF/MF confere o preço e a quantidade indicados na fatura comercial. As informações sobre a quantidade (peso e unidade) também estão disponíveis no conhecimento de carga e no romaneio de carga. A classificação da mercadoria na Nomenclatura Comum do Mercosul (NCM), baseada no SH, é verificada para fins de tributação, mas não é conferida com base nos documentos citados, por não ser obrigatória a sua indicação na fatura comercial. Algumas vezes, mesmo quando o código é incluído, são declarados apenas os quatro primeiros dígitos.

Para agilizar o despacho aduaneiro, a SRF/MF seleciona as DIs em quatro canais de conferência:

i. verde: aplicado para firmas com cadastro limpo e que importam regularmente, sendo a mercadoria liberada sem qualquer verificação; ${ }^{6}$

ii. amarelo: a DI é conferida com base nas informações contidas no conhecimento de carga, romaneio de carga e fatura comercial;

\footnotetext{
${ }^{6}$ Os documentos podem ser solicitados pela SRF após a liberação da mercadoria, sendo obrigatório manter sua posse por pelo menos cinco anos.
} 


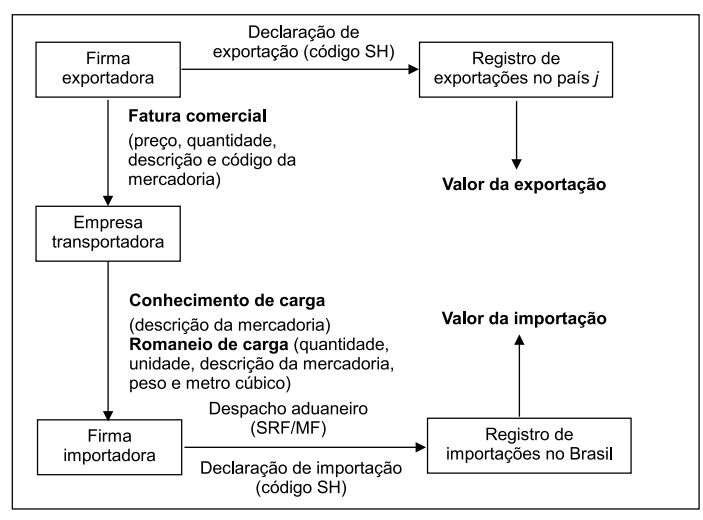

Elaboração dos autores

Figura 1: Registro das exportações e das importações do produto $i$

iii. vermelho: além de conferir as informações dos documentos, é feita uma verificação física da mercadoria; e

iv. cinza: conferência dos documentos, verificação física e aplicação de procedimento especial para detectar indícios de fraude, inclusive no preço declarado da mercadoria.

Se o subfaturamento é comprovado, a SRF/MF deveria aplicar uma multa equivalente a $100 \%$ da diferença entre o valor efetivo e o valor declarado, além de exigir o pagamento do imposto devido acrescido dos juros de mora (Sosa 1993, p. 241). No entanto, a SRF/MF tem aplicado a penalidade de perda total (apreensão) da mercadoria, o que tem sido objeto de contestação judicial (Ponciano 2007).

A firma exportadora, por sua vez, registra as informações na declaração de exportação no seu país, informando o preço unitário, a quantidade, o peso e o valor total, e o código do SH. À exceção do último, todas as informações devem ser iguais às da fatura comercial entregue ao importador.

Quanto à classificação da mercadoria no $\mathrm{SH}$, no Brasil, a responsabilidade legal é do importador, cabendo à SRF/MF verificar sua exatidão. No país de procedência, cabe à firma exportadora efetuar a classificação. Assim, como os registros de exportação e importação são efetuados independentemente, os códigos do SH podem ser diferentes, principalmente para os produtos cuja descrição é complexa e exige conhecimentos técnicos. Esses erros são de natureza involuntária.

Portanto, se os registros de exportação e importação são baseados nas informações contidas na fatura comercial, não há possibilidade de ocorrerem divergências sistemáticas nas declarações de preço, quantidade, peso e valor total, exceto na presença de fraudes: a empresa importadora registra um preço e/ou quantidade inferior ao verificado efetivamente, com o intuito de reduzir o valor do imposto de importação a ser recolhido. ${ }^{7}$

\footnotetext{
${ }^{7}$ Como as vendas externas geralmente não são tributadas, as firmas exportadoras podem declarar um valor superior ao efetivamente exportado para desonerar parte das suas vendas no mercado interno. Essa prática não é usual, pois é fortemente fiscalizada pela administração fazendária do país exportador.
} 


\subsection{Metodologia e fonte de dados}

A evasão das importações é medida pela diferença entre o valor de exportação registrado nos países de procedência e o valor de importação declarado pelo Brasil, ${ }^{8}$ por produto classificado a seis dígitos no SH de 2002 (SH6-2002), ambos medidos a preços FOB. Assim, temos que:

$$
E V_{i}=\log X_{i}-\log M_{i}
$$

onde $E V_{i}=$ valor da evasão das importações; $X_{i}=$ valor total FOB das exportações do produto $i$ registrado nos países de procedência; e $M_{i}=$ valor total das importações FOB do produto $i$ declarado pelo Brasil.

O subfaturamento das importações pode ser feito mediante a declaração de um preço inferior ao preço efetivamente pago ou de uma quantidade inferior à quantidade adquirida. Uma vez que o acesso às informações sobre quantidades em unidades não é disponível, não foi possível verificar qual dos dois procedimentos é mais adotado pelos importadores brasileiros. A quantidade disponível é o peso que consta em todos os documentos, sendo mais facilmente controlado.

Uma terceira maneira de reduzir o valor das importações é beneficiar-se de uma tarifa menor, alterando a classificação do produto. Para que esse procedimento não seja detectado pela fiscalização aduaneira, é necessária a existência de pelo menos um produto similar, sobre o qual incida uma tarifa mais baixa (tarifa do produto similar).

Neste trabalho, os produtos na classificação SH6 pertencentes à mesma posição SH4 são considerados similares, conforme ilustrado na Tabela 1. Na classificação 85.10 (SH4), há três aparelhos ou máquinas elétricas que se diferenciam pelo uso final, além das suas partes. As importações de aparelhos ou máquinas de barbear (8510.10) pagam uma tarifa de $20 \%$ e aqueles para depilação (8510.30) pagam uma tarifa de $16 \%$. As máquinas de cortar cabelo ou tosquiar têm uma tarifa nula. Neste caso, os importadores de aparelhos de barbear e de depilar podem classificar tais bens no código referente a máquinas para cortar cabelo ou tosquiar, esquivando-se, assim, de pagar um imposto bem mais elevado. Desta forma, a menor tarifa (mínima) entre os produtos $\mathrm{SH} 6$ pertencentes a um SH4, no exemplo de $0 \%$, será considerada como a tarifa de produtos similares.

Existe ainda a possibilidade de que tanto o exportador como o importador entrem em acordo a respeito do valor comercializado a ser declarado. Neste caso, porém, a metodologia adotada não é capaz de detectar a evasão.

Os dados de valor da exportação para o mercado brasileiro por país foram obtidos de World Integrated Trade Solution (WITS), que disponibiliza a base de dados de comércio do Commodity Trade Statistics (Comtrade) das Nações Unidas, organizada com base nas informações cedidas por cada país. Os valores de importação do Brasil por país de procedência foram obtidos da SRF/MF. Para que as informações por produto fossem compatíveis, foi escolhida a classificação de mercadorias do SH-2002 ao nível de seis dígitos (SH6-2002), que é

\footnotetext{
${ }^{8}$ A diferença entre os valores de exportação e de importação pode também ser devida a mercadorias em trânsito, isto é, à saída de mercadorias registrada no país exportador em um determinado ano, mas não internalizada no país importador no mesmo ano. Em 2003, este efeito não foi importante, pois as importações apresentaram um aumento de apenas 2,2\% em relação ao ano anterior.
} 
Tabela 1: Produtos similares e a mudança na classificação

\begin{tabular}{rlr}
\hline Código & \multicolumn{1}{c}{ Descrição } & $\begin{array}{c}\text { Imposto de } \\
\text { importação (\%) }\end{array}$ \\
\hline 85,10 & $\begin{array}{l}\text { Aparelhos ou máquinas de barbear e cortar o } \\
\text { cabelo ou de tosquiar, e aparelhos de depilar, }\end{array}$ \\
& de motor elétrico incorporado & \\
8510,10 & Aparelhos ou máquinas de barbear & 20 \\
8510,20 & Máquinas de cortar cabelo ou tosquiar & 0 \\
8510,30 & Aparelhos de depilar & 16 \\
8510,90 & Partes - De aparelhos ou máquinas de & 6 \\
& barbear & 0 \\
\hline
\end{tabular}

Fonte: Tarifa externa comum do Mercosul.

idêntico para todos os países, ainda que os dados do Brasil estejam disponíveis a oito dígitos (NCM8-2002). ${ }^{9}$

Os fluxos de comércio em dólares medidos a preços FOB são de 2003. O ano escolhido não deve influenciar a análise, pois apesar da existência de dados para cada ano no período entre 2002 e 2006, as tarifas não sofreram alterações importantes e a utilização dos dados em painel seria inviável.

Foram escolhidos 96 países exportadores ${ }^{10}$ com dados em SH-2002 naquele ano. As importações registradas no Brasil originárias deste grupo de países atingiram US $\$ 43,3$ bilhões, correspondentes a $90,7 \%$ do total geral de 2003.

A classificação SH6-2002 dispõe de 5.224 produtos, dos quais 615 foram eliminados: 265 devido à inexistência de comércio entre o Brasil e os países escolhidos e 350 por indicarem exportações ou importações nulas. Estes produtos correspondem a um comércio de apenas US $\$ 164,5$ milhões.

A SRF/MF também disponibilizou as informações sobre o imposto de importação calculado, efetivamente pago (arrecadado) e o valor tributável ${ }^{11}$ base de cálculo dos impostos incidentes nas compras externas - por produto em SH8-2002, posteriormente agregadas para seis dígitos. As tarifas aduaneiras calculadas e pagas dos produtos foram obtidas dividindo-se, respectivamente, os valores dos impostos calculados e arrecadados pelo valor tributável. Portanto, as tarifas calculadas e pagas dos produtos a seis dígitos correspondem à média ponderada das respectivas alíquotas ao nível de oito dígitos.

A tarifa calculada corresponde à alíquota fixada na legislação. ${ }^{12} \mathrm{~A}$ tarifa

\footnotetext{
${ }^{9}$ O Sistema Harmonizado de classificação de mercadorias no comércio exterior é adotado por todos os países. Assim, os primeiros seis dígitos são idênticos para todos, podendo cada país adicionar mais dígitos segundo a sua conveniência. Por exemplo, o Mercosul adota oito dígitos (NCM-8), e os Estados Unidos, dez.

${ }^{10}$ Não foram incluídos os países que dispõem somente de dados no SH-1996, devido a dificuldades de compatibilização com o SH-2002: Filipinas, Indonésia, Iraque, Nigéria, Noruega, Taiwan, Ucrânia e Venezuela.

${ }^{11} \mathrm{O}$ valor tributável e o valor de importação geralmente são iguais, exceto quando a SRF/MF detecta que o preço da DI não corresponde ao verdadeiro preço da transação.

${ }^{12}$ Nas importações também são pagos o Imposto sobre Produtos Industrializados (IPI) e o Imposto sobre a Circulação de Mercadorias e Serviços (ICMS). Os dois impostos indiretos não foram incluídos na análise por serem tributos que incidem sobre o valor adicionado, sendo escriturados para fins fiscais na forma de crédito e débito. Desta forma, se for reduzido na importação, o crédito será menor e, posteriormente, na venda do produto final, o saldo líquido a ser pago será
} 
Tabela 2: Estatísticas descritivas das variáveis

\begin{tabular}{lccccc}
\hline Variável & Média & Desvio padrão & Mínimo & Máximo & $\mathrm{N}^{\circ}$ obs. \\
\hline$X($ US\$ 1.000$)$ & 9.399 & 51.717 & 0,00 & 1.873 .333 & 4609 \\
$M($ US 1.000$)$ & 8.957 & 39.438 & 0,00 & 1.002 .196 & 4609 \\
$E V=\log X-\log Y$ & 0,27 & 1,51 & $(9,68)$ & 9,93 & 4609 \\
$T C$ & 0,13 & 0,06 & 0,00 & 0,51 & 4609 \\
$T P$ & 0,10 & 0,07 & 0,00 & 0,38 & 4609 \\
$T P S$ & 0,05 & 0,06 & 0,00 & 0,28 & 4609 \\
$B D_{1}$ & 0,63 & 0,48 & 0,00 & 1,00 & 4609 \\
$B D_{2}$ & 0,60 & 0,49 & 0,00 & 1,00 & 4609 \\
\hline
\end{tabular}

Fonte: Dados brutos: exportação - Comtrade; importação, tarifa calculada e paga SRF/MF; bem diferenciado - Rauch (1999).

Elaboração dos autores.

$X=$ valor das exportações; $M=$ valor das importações; $\log X=\log$ aritmo do valor das exportações; $\log M=\log$ aritmo do valor das importações; $E V=$ diferença entre $\log X$ e $\log M ; T C=$ tarifa calculada; $T P=$ tarifa paga; $T P S=$ tarifa paga de produto similar; $B D 1$ = variável dicotômica que minimiza o número de bens homogêneos; $B D 2=$ variável dicotômica que minimiza o número de bens diferenciados.

paga refere-se àquela efetivamente recolhida pelas autoridades aduaneiras, podendo diferir da calculada devido aos regimes especiais de tributação na importação. Em 2003, as importações realizadas por meio de regimes especiais de tributação atingiram $29,1 \%$ do total, sendo os principais benefícios concedidos à atividade exportadora (drawback e Regime Aduaneiro Especial de Entreposto Industrial sob Controle Informativo), à produção industrial na Zona Franca de Manaus e à indústria automotiva (Piani \& Miranda 2006).

A Tabela 2 mostra as estatísticas descritivas das variáveis utilizadas. Notese que o valor médio das exportações atinge US\$ 9,4 milhões, contra US\$ 8,9 milhões das importações, gerando uma diferença média de US\$ 0,5 milhão. Este resultado indica que há uma diferença de aproximadamente US\$2 bilhões entre o valor total das exportações registradas pelos parceiros comerciais e o valor das importações declaradas no Brasil. ${ }^{13}$

As tarifas calculadas e pagas apresentam uma média simples de, respectivamente, $13,3 \%$ e $9,6 \%$ e os valores máximos atingem $50,9 \%$ e $37,7 \%$.

A tarifa paga de produtos similares varia entre $0 \%$ e $28,3 \%$, com média de $5 \%$.

As características específicas de alguns bens que os tornam diferenciados dificultam a fiscalização pelas autoridades aduaneiras, tanto para a identificação de subcotação do preço como para a identificação da classificação incorreta do produto. Como a seleção dos produtos SH6 que podem ser considerados diferenciados é uma tarefa complexa, optou-se por adotar a classificação efetuada por Rauch (1999).

Esse autor dividiu os setores a quatro dígitos da Classificação Uniforme de Comércio Internacional (CUCI-4) em três grupos. O primeiro deles, denominado produtos homogêneos, contém bens com preços cotados em mercados

maior. Portanto, o ganho obtido com o menor pagamento destes impostos na importação será apenas de natureza financeira. Assim, supõe-se que a decisão de omitir uma fração do valor das importações é determinada unicamente pelo nível da tarifa aduaneira.

${ }^{13}$ A magnitude real da evasão tarifária é, por sua própria natureza, de difícil observação. As estimativas de seu valor total para 2003, de acordo com a desagregação a dois dígitos do SH, indicam uma concentração em determinados setores como, por exemplo, combustíveis minerais, máquinas e equipamentos, produtos químicos, óleos e perfumes, vestuário e brinquedos. 
Tabela 3: Distribuição de frequência das tarifas calculadas e pagas e da evasão média

\begin{tabular}{|c|c|c|c|c|c|c|}
\hline \multirow[t]{2}{*}{ Classe } & \multicolumn{3}{|c|}{ Tarifa calculada $\left(T_{C}\right)$} & \multicolumn{3}{|c|}{ Tarifa paga (TP) } \\
\hline & $\begin{array}{l}\text { Evasão média } \\
(\log X-\log M)\end{array}$ & $\begin{array}{c}\mathrm{N}^{\circ} \\
\text { prods. } \\
\text { SH6 }\end{array}$ & $(\%)$ & $\begin{array}{c}\text { Evasão média } \\
(\log X-\log M)\end{array}$ & $\begin{array}{c}\mathrm{N}^{\mathrm{o}} \\
\text { prods. } \\
\text { SH6 }\end{array}$ & $(\%)$ \\
\hline $0 \leq T<5$ & 0,06 & 640 & 13,9 & 0,08 & 1413 & 30,7 \\
\hline $5 \leq T<10$ & 0,07 & 552 & 12,0 & 0,10 & 989 & 21,5 \\
\hline $10 \leq T<15$ & 0,23 & 1267 & 27,5 & 0,31 & 1099 & 23,8 \\
\hline $15 \leq T<20$ & 0,37 & 1588 & 34,4 & 0,63 & 852 & 18,5 \\
\hline $20 \leq T<25$ & 0,57 & 514 & 11,1 & 0,64 & 230 & 5,0 \\
\hline $25 \leq T<30$ & 0,64 & 14 & 0,3 & 1,76 & 8 & 0,2 \\
\hline $30 \leq \mathrm{T}$ & 0,10 & 34 & 0,7 & 0,28 & 18 & 0,4 \\
\hline Total & 0,27 & 4609 & 100,0 & 0,27 & 4609 & 100,0 \\
\hline
\end{tabular}

organizados. Como exemplos, podem-se citar soja e trigo, que têm seus preços determinados na Bolsa de Mercadorias de Chicago e o cobre eletrolítico, na Bolsa de Metais de Londres. O segundo é composto por produtos com preços referenciados, os quais são disponibilizados em publicações especializadas. Neste caso, destacam-se fertilizantes e produtos químicos, com preços disponíveis no ICIS Pricing - fertilizers and chemical products, publicado pela Reed Business Information Limited. O terceiro grupo abrange os bens diferenciados.

Uma vez que a fiscalização aduaneira tem maior controle sobre o preço e a classificação dos produtos pertencentes aos dois primeiros grupos, optou-se neste trabalho pela utilização de uma variável binária denominada $B D$, que assume valor um quando o bem pertence ao terceiro grupo.

Como há algum grau de arbitrariedade na definição dos bens, (Rauch 1999) adotou duas classificações. A primeira $\left(B D_{1}\right)$ minimiza o número de setores classificados como homogêneos, ocorrendo o contrário com o segundo $\left(B D_{2}\right)$. Para caracterizar os bens na classificação SH6, foi feita a compatibilização com a CUCI-4. Em $B D_{1}$ há 2.897 produtos $\mathrm{SH6}$ considerados diferenciados e, em $B D_{2}, 2.762$ bens.

Por último, a Tabela 3 apresenta a distribuição de frequência das tarifas calculadas e pagas e para cada classe de tarifa, a evasão média (em $\log$ ). Notase uma alta concentração de produtos com tarifa calculada entre $15 \%$ e $20 \%$; apenas 48 produtos (1\%) são favorecidos com uma alíquota acima de $25 \%$. Como esperado, devido aos regimes especiais de tributação na importação, $76 \%$ dos produtos mostram uma tarifa paga inferior a $15 \%$. Em ambos os casos (TC e $\left.T_{P}\right)$, há uma grande variabilidade de alíquotas entre os produtos SH6. A evasão média aumenta tanto com a tarifa calculada quanto com a tarifa paga, com exceção da última classe.

\section{Evidência empírica}

\subsection{Equação básica}

Inicialmente, testa-se a hipótese de que a diferença entre o valor das exportações registradas pelos países de procedência e o das importações declaradas 
Tabela 4: Efeitos das tarifas de importação sobre a evasão

\begin{tabular}{|c|c|c|c|c|c|}
\hline & (1) & (2) & (3) & (4) & (5) \\
\hline$T_{C}$ & $\begin{array}{l}2,386^{*} \\
(0,37)\end{array}$ & - & - & - & - \\
\hline$T_{P}$ & - & $\begin{array}{c}3,082^{*} \\
(0,36)\end{array}$ & $\begin{array}{c}3,917^{*} \\
(0,37)\end{array}$ & $\begin{array}{c}3,127^{*} \\
(0,36)\end{array}$ & $\begin{array}{l}3,805^{*} \\
(0,37)\end{array}$ \\
\hline Constante & $\begin{array}{r}-0,05 \\
(0,05)\end{array}$ & $\begin{array}{l}0,02 \\
(0,04)\end{array}$ & $\begin{array}{c}-0,142^{*} \\
(0,04)\end{array}$ & $\begin{array}{c}0,03 \\
(0,38)\end{array}$ & $\begin{array}{l}0,127^{*} \\
(0,04)\end{array}$ \\
\hline Exclusão & Não & Não & $\mathrm{T}_{P}=0$ & $\begin{array}{l}2 \% \text { maiores e } \\
2 \% \text { menores } \\
\text { valores de } \\
\text { evasão }\end{array}$ & $\begin{array}{l}T_{P}=0 \\
2 \% \text { maiores e } \\
2 \% \text { menores } \\
\text { valores de } \\
\text { evasão }\end{array}$ \\
\hline $\mathrm{N}^{\circ}$ obs. & 4609 & 4609 & 4318 & 4517 & 4250 \\
\hline$R^{2}$ & 0,01 & 0,02 & 0,03 & 0,02 & 0,03 \\
\hline
\end{tabular}

\footnotetext{
Elaboração dos autores.

${ }^{1} T_{C}=$ tarifa calculada e $T_{P}=$ tarifa paga.

${ }^{2}$ Erro padrão robusto entre parênteses.

${ }^{3}$ Os indicadores ${ }^{* * *},{ }^{* *} \mathrm{e}^{*}$ apontam o grau de significância de, respectivamente, $10 \%, 5 \%$ e $1 \%$.
}

no Brasil (evasão) está associada ao nível da tarifa. Assim, a equação básica a ser estimada é:

$$
E V_{i}=a_{0}+a_{1} T_{i}+e_{i}
$$

na qual o principal parâmetro a ser estimado é $a_{1}$ - cujo sinal esperado é positivo $-T_{i}$ representa a tarifa calculada ou paga e $e_{i}$ o termo de erro.

Os resultados são apresentados na Tabela 4. Nas colunas (1) e (2) utilizamse, respectivamente, as tarifas calculadas e as tarifas efetivamente pagas. As duas medidas apresentam coeficientes positivos e significativos ao nível de $1 \%$.

Considerando a tarifa paga como a variável relevante, em virtude do conhecimento das empresas quanto ao seu enquadramento nos regimes especiais de tributação, a estimativa indica que um aumento de um ponto de porcentagem na tarifa eleva a diferença entre o valor das exportações e das importações em 3,1\%. Vale observar que a constante não difere significativamente de zero, indicando que quando a tarifa paga é nula, o valor da exportação e o da importação são estatisticamente iguais.

Na coluna (3) excluem-se os produtos com tarifa nula, pois neste caso não há motivação para subfaturar as importações. O coeficiente estimado da tarifa aumenta para 3,9, significativo ao nível de $1 \%$, mas é estatisticamente diferente de 3,1 apenas ao nível de $10 \% .{ }^{14}$

Para verificar a robustez das estimativas obtidas, na coluna (4) são subtraídos da amostra $2 \%$ dos produtos com os maiores e $2 \%$ com os menores valores de evasão das importações ${ }^{15}$ - na última coluna (5) retiram-se também os que apresentam tarifas nulas. Nestas estimativas, não é rejeitada a hipótese nula

\footnotetext{
${ }^{14}$ Eliminando-se todos os produtos com tarifa igual ou inferior a 2,5\%, o coeficiente permanece constante.

${ }^{15}$ Resultados semelhantes são obtidos quando retirado da amostra $1 \%$ dos produtos com maiores e menores valores de evasão fiscal.
} 
de que os coeficientes sejam, respectivamente, iguais àqueles obtidos nas colunas (2) e (3).

Por último, nota-se que o grau de ajustamento das regressões $\left(R^{2}\right)$ é pequeno, provavelmente devido a erros na classificação ou na imputação do país de procedência do produto.

Um método tradicional para a redução de ruídos é a agregação dos dados. Para ilustrar esse argumento, seguindo um procedimento similar ao de Fisman \& Wei (2004), os produtos foram distribuídos em 23 classes, com intervalos de um ponto de percentagem entre as tarifas pagas, à exceção do último, que abrange todos os produtos com alíquota igual ou superior a $22 \%$. Em seguida, a equação básica foi novamente estimada e os resultados são apresentados na Tabela 5. Os coeficientes obtidos são estatisticamente iguais a 3,1, independente do método de agregação ou mesmo quando se procede a uma ponderação pelo número de produtos em cada classe de tarifa. Como esperado, o $\mathrm{R}^{2}$ aumenta substancialmente, atingindo valores entre $65 \%$ e $71 \%{ }^{16}$.

Tabela 5: Efeito das tarifas de importação sobre a evasão - dados agregados por classes de tarifas

\begin{tabular}{|c|c|c|c|c|}
\hline & (1) & (2) & (3) & (4) \\
\hline$\overline{\mathrm{T}_{P}}$ & $\begin{array}{l}3,087^{*} \\
(0,697)\end{array}$ & $\begin{array}{l}3,180^{*} \\
(0,617)\end{array}$ & $\begin{array}{l}2,726^{*} \\
(0,528)\end{array}$ & $\begin{array}{l}2,640^{*} \\
(0,478)\end{array}$ \\
\hline Constante & $\begin{array}{r}-0,051 \\
(0,075)\end{array}$ & $\begin{array}{r}-0,024 \\
(0,039)\end{array}$ & $\begin{array}{c}-0,153^{*} \\
(0,055)\end{array}$ & $\begin{array}{c}-0,134^{*} \\
(0,061)\end{array}$ \\
\hline Método de agregação & Média & Média & Mediana & Mediana \\
\hline Ponderação pelo $\mathrm{n}^{\circ}$ obs. & Não & Sim & Não & Sim \\
\hline No observações & 23 & 23 & 23 & 23 \\
\hline$R^{2}$ & 0,653 & 0,662 & 0,708 & 0,696 \\
\hline
\end{tabular}

Símbolos: $\mathrm{T}_{P}=$ tarifa paga.

Notas: desvio-padrão robusto entre parênteses. Os indicadores ${ }^{* * *},{ }^{* *} \mathrm{e}^{*}$ indicam o grau de significância de, respectivamente, $10 \%, 5 \%$ e $1 \%$.

\subsection{Equação com diferenciação do produto}

A seguir, à equação básica são acrescentadas duas variáveis: uma dummy que indica se o produto é diferenciado e outra - uma combinação da dummy com a tarifa - para verificar se as características do produto influenciam nas decisões de subfaturamento. Tem-se, então:

$$
E V_{i}=a_{0}+a_{1} T_{i}+a_{2} B D_{i}+a_{3} B D_{i} \times T_{i}+e_{i}
$$

Na equação, $B D_{i}$ representa a dummy, que assume o valor 1 se o produto é diferenciado.

Os resultados são exibidos na Tabela 6. Na coluna (1) é reproduzida a estimativa da equação básica para fins de comparação. Nas colunas (2) e (4) são apresentadas as estimativas da equação (2), utilizando-se as duas definições de bens diferenciados. No entanto, em ambos os casos os coeficientes $a_{2}$ e $a_{3}$ não são estatisticamente significativos.

\footnotetext{
${ }^{16}$ Javorcik e Javorcik \& Narciso (2008) estimam o mesmo modelo para 10 países da Europa Oriental e obtém um $\mathrm{R}^{2}$ neste patamar quando introduzem o efeito fixo para cada país.
} 
Como a estrutura tarifária contempla os bens diferenciados com maiores níveis de proteção, há uma correlação elevada entre $B D_{1}$ e $B D_{1} \times T_{P}$ e entre $B D_{2}$ e $B D_{2} \times T_{P}$ de, respectivamente, $85 \%$ e $68 \%$, tornando os estimadores menos eficientes. Para contornar este problema, reestimou-se a equação (2), retirando-se a variável dummy $B D$, o que equivale a presumir que o intercepto mantém-se constante, mas a inclinação aumenta com a tarifa quando o produto é diferenciado.

Os resultados obtidos nas colunas (3) e (5) apresentam estimativas de $a_{3}$ semelhantes, ainda que mostrem menos precisão quando é utilizada a variável $B D_{1}$, a qual minimiza a presença de produtos homogêneos.

Tabela 6: Efeito das tarifas de importação sobre a evasão, com diferenciação dos produtos

\begin{tabular}{|c|c|c|c|c|c|}
\hline & (1) & (2) & (3) & (4) & (5) \\
\hline$T_{P}$ & $\begin{array}{c}3,082^{*} \\
(0,36)\end{array}$ & $\begin{array}{c}2,222^{*} \\
(0,68)\end{array}$ & $\begin{array}{c}2,274^{*} \\
(0,57)\end{array}$ & $\begin{array}{c}2,242^{*} \\
(0,65)\end{array}$ & $\begin{array}{c}2,175^{*} \\
(0,55)\end{array}$ \\
\hline$B D$ & & $\begin{array}{l}0,01 \\
(0,78)\end{array}$ & & $\begin{array}{l}0,02 \\
(0,08)\end{array}$ & \\
\hline$B D \times T_{P}$ & & $\begin{array}{l}1,02 \\
(0,82)\end{array}$ & $\begin{array}{c}0,934^{* * *} \\
(0,50)\end{array}$ & $\begin{array}{l}0,96 \\
(0,80)\end{array}$ & $\begin{array}{l}1,071^{*} \\
(0,48)\end{array}$ \\
\hline Constante & $\begin{array}{l}0,02 \\
(0,04)\end{array}$ & $\begin{array}{l}0,00 \\
(0,06)\end{array}$ & $\begin{array}{l}0,01 \\
(0,04)\end{array}$ & $\begin{array}{l}0,02 \\
(0,05)\end{array}$ & $\begin{array}{l}0,01 \\
(0,04)\end{array}$ \\
\hline $\begin{array}{l}\text { Bem } \\
\text { diferenciado }\end{array}$ & & $B D_{1}$ & $B D_{1}$ & $B D_{2}$ & $B D_{2}$ \\
\hline $\mathrm{N}^{\circ}$ obs. & 4.609 & 4.609 & 4.609 & 4.609 & 4.609 \\
\hline$R^{2}$ & 0,02 & 0,02 & 0,02 & 0,02 & 0,02 \\
\hline $\begin{array}{l}\text { Elaboração dos } \\
{ }^{1} \mathrm{~T}_{P}=\text { tarifa pą } \\
\text { de produtos ho } \\
\text { número de pro } \\
{ }^{2} \text { Erro padrão ro } \\
{ }^{3} \text { Os indicadores } \\
\text { respectivamen }\end{array}$ & $\begin{array}{l}\text { utores. } \\
\mathrm{BD}_{1}=\text { be } \\
\text { nogêneos; } \\
\text { utos homo } \\
\text { usto entre } \\
{ }^{* *}{ }^{* *} \mathrm{e}^{*} \text { at }\end{array}$ & $\begin{array}{l}m \text { diferenc } \\
\mathrm{D}_{2}=\text { bem } \\
\text { yêneos. } \\
\text { parênteses } \\
\text { ontam o g. } \\
\text { e } 1 \% \text {. }\end{array}$ & $\begin{array}{l}\text { lo, ma } \\
\text { ferenc } \\
\text { de si }\end{array}$ & $\begin{array}{l}\text { zando } \\
\text { mini }\end{array}$ & $\begin{array}{l}\text { número } \\
\text { izando o }\end{array}$ \\
\hline
\end{tabular}

As estimativas obtidas indicam que se a tarifa aduaneira aumenta em um ponto de porcentagem, a diferença entre os valores de exportação e de importação se eleva em 2,2\% para produtos homogêneos e 3,2\% para produtos diferenciados. Assim, os importadores destes últimos bens têm maior incentivo para a prática de subfaturamento das importações, uma vez que percebem as maiores dificuldades de verificação das informações pelos fiscais aduaneiros.

\subsection{Mudança na classificação}

Como mostrado na seção anterior, é possível que na presença de produtos similares com tarifas menores o importador efetue a classificação do produto na categoria com alíquota inferior, para se beneficiar do diferencial de tarifas. No intuito de testar esta possibilidade, estimou-se a seguinte equação:

$$
E V_{i}=a_{0}+a_{1} T_{i}+a_{2} B D_{i} \times T_{i}+a_{3} T_{P M I N i}+a_{4} B D_{i} \times T_{P M I N i}+e_{i}
$$

No caso, $T_{P M I N i}$ é a tarifa do produto similar. 
Tabela 7: Efeito das tarifas de importação sobre a evasão, por diferenciação dos produtos e possibilidade de mudança na classificação

\begin{tabular}{|c|c|c|c|c|c|}
\hline & (1) & (2) & (3) & (4) & (5) \\
\hline$\overline{\mathrm{T}_{P}}$ & $\begin{array}{c}2,175^{*} \\
(0,55)\end{array}$ & $\begin{array}{c}2,412^{*} \\
(0,63)\end{array}$ & $\begin{array}{c}2,126^{*} \\
(0,77)\end{array}$ & $\begin{array}{c}2,189^{*} \\
(0,55)\end{array}$ & $\begin{array}{c}3,712^{*} \\
(0,65)\end{array}$ \\
\hline$B D \times T_{P}$ & $\begin{array}{c}1,071^{*} \\
(0,48)\end{array}$ & $\begin{array}{c}1,153^{*} \\
(0,50)\end{array}$ & $\begin{array}{l}1,610^{* * *} \\
(0,85)\end{array}$ & $\begin{array}{c}1,545^{* *} \\
(0,66)\end{array}$ & $\begin{array}{c}1,535^{* *} \\
(0,69)\end{array}$ \\
\hline$T_{P M I N}$ & & $\begin{array}{r}-0,57 \\
(0,60)\end{array}$ & $\begin{array}{l}0,16 \\
(1,19)\end{array}$ & & \\
\hline$B D \times T_{P M I N}$ & & & $\begin{array}{l}1,00 \\
(1,37)\end{array}$ & $\begin{array}{l}0,85 \\
(0,69)\end{array}$ & $\begin{array}{c}-1,930^{*} \\
(0,79)\end{array}$ \\
\hline Constante & $\begin{array}{l}0,01 \\
(0,04)\end{array}$ & $\begin{array}{l}0,01 \\
(0,04)\end{array}$ & $\begin{array}{l}0,01 \\
(0,04)\end{array}$ & $\begin{array}{l}0,01 \\
(0,04)\end{array}$ & $\begin{array}{c}-0,192^{*} \\
(0,05)\end{array}$ \\
\hline Exclusão & Não & Não & Não & Não & $\begin{array}{l}T_{P}=0 \mathrm{e} \\
T_{P}=T_{P M I N}\end{array}$ \\
\hline $\mathrm{N}^{\circ}$ obs. & 4609,00 & 4609,00 & 4609,00 & 4609,00 & 3263,00 \\
\hline$R^{2}$ & 0,02 & 0,02 & 0,02 & 0,02 & 0,03 \\
\hline
\end{tabular}

Elaboração dos autores.

${ }^{1} \mathrm{~T}_{P}=$ tarifa paga; $\mathrm{BD}=$ bem diferenciado; $\mathrm{T}_{P M I N}=$ tarifa de produto similar.

${ }^{2}$ Erro padrão robusto entre parênteses.

${ }^{3}$ Os indicadores ${ }^{* * *},{ }^{* *} \mathrm{e}^{*}$ apontam o grau de significância de, respectivamente, $10 \%$, $5 \%$ e $1 \%$.

Os resultados ${ }^{17}$ são mostrados na Tabela 7. Na coluna (1), são reproduzidos os resultados da coluna (5) da Tabela anterior para fins de comparação. Os coeficientes $a_{3}$ e $a_{4}$, nas colunas (2) a (4), não são estatisticamente significativos, inclusive quando as variáveis são incluídas de forma isolada na equação.

Quando as tarifas de produtos similares são iguais ou a alíquota do produto e/ou a tarifa deste bem é nula, não há motivação para mudar a classificação do produto. Dessa forma, na coluna (5) excluem-se os produtos nesta situação. O resultado mostra que para os produtos diferenciados o coeficiente estimado $^{18}$ é negativo e significativo a $1 \%$. Vale notar que, nesta especificação, devido à eliminação dos produtos com tarifa nula, o coeficiente da tarifa paga atinge 3,7, magnitude igual à obtida na equação básica sob a mesma condição (coluna 3 da Tabela 4).

\subsection{Forma funcional}

Para verificar se o impacto de um aumento na tarifa sobre a evasão fiscal é diferenciado segundo os níveis de alíquota do imposto de importação, a amostra foi dividida em quartis, o primeiro com tarifas inferiores a 3,6\%, o segundo entre $3,6 \%$ e $9,5 \%$, o terceiro com tarifas superiores a 9,5\% e inferiores a $14,7 \%$, e o quarto com tarifas acima de $14,7 \%$. Os resultados apresentados na Tabela 8 mostram que, nos dois primeiros quartis, o efeito é estatisticamente nulo e que no último quartil é significativo e superior ao terceiro, indicando a

\footnotetext{
${ }^{17}$ As estimativas utilizando a definição de bem diferenciado 1 são idênticas e estão disponíveis aos interessados por solicitação aos autores.

${ }^{18}$ Alguns autores ( Fisman \& Wei (2004) e Mishra et al. (2007) ) realizam o mesmo exercício utilizando a tarifa média ponderada pelas importações de produtos similares. Neste trabalho, considerou-se a tarifa mínima de produto similar como a medida mais apropriada para representar a oportunidade de uma classificação alternativa para o importador. A utilização da tarifa média ponderada não gerou estimativas estatisticamente significativas.
} 
presença de um custo fixo para a prática de evasão fiscal. Este é superado apenas com níveis de tarifas enquadradas no terceiro quartil ou quando o ganho com a evasão aumenta mais que o custo, conforme o imposto de importação cresce.

Tabela 8: Efeito das tarifas de importação sobre a evasão, por quartil de tarifas

\begin{tabular}{|c|c|c|}
\hline Classe de tarifa & (1) & $(2)$ \\
\hline $1^{\circ}$ quartil: $0 \leq T_{P}<0,0357$ & $\begin{array}{r}-3,105 \\
(3,292)\end{array}$ & $\begin{array}{l}6,618 \\
(4,293)\end{array}$ \\
\hline $2^{\circ}$ quartil: $0,0357 \leq T_{P}<0,095$ & $\begin{array}{r}-0,567 \\
(0,997)\end{array}$ & $\begin{array}{l}2,708 \\
(1,397)\end{array}$ \\
\hline $3^{\circ}$ quartil: $0,095 \leq T_{P}<0,1469$ & $\begin{array}{l}1,738^{*} \\
(0,635)\end{array}$ & $\begin{array}{l}3,562^{*} \\
(0,918)\end{array}$ \\
\hline $4^{\circ}$ quartil: $0,1469 \leq T_{P}<0,3766$ & $\begin{array}{l}2,623^{*} \\
(0,418)\end{array}$ & $\begin{array}{l}3,786^{*} \\
(0,728)\end{array}$ \\
\hline$B D_{2} \times T_{P}$ & & $\begin{array}{l}1,516^{* *} \\
(0,694)\end{array}$ \\
\hline$B D_{2} \times T_{P M I N}$ & & $\begin{array}{c}-2,000^{* *} \\
(0,797)\end{array}$ \\
\hline Constante & $\begin{array}{c}0,120^{*} \\
(0,06)\end{array}$ & $\begin{array}{c}-0,178^{* *} \\
(0,087) \\
\end{array}$ \\
\hline Exclusão & Não & $\begin{array}{l}T_{P}=0 \mathrm{e} \\
T_{P}=T_{P M I N}\end{array}$ \\
\hline No observações & 4.609 & 3.263 \\
\hline$R^{2}$ & 0,021 & 0,022 \\
\hline \multicolumn{3}{|c|}{$\begin{array}{l}\text { Elaboração dos autores. } \\
{ }^{1} T_{P}=\text { tarifa paga; } B D_{2}=\text { bem diferenciado; } T_{P M I N}=\text { tarifa de } \\
\text { produto similar. } \\
2 \text { Erro padrão robusto entre parênteses. } \\
{ }^{3} \text { Os indicadores }{ }^{* * *},{ }^{* *} \mathrm{e}^{*} \text { apontam o grau de significância de, } \\
\text { respectivamente, } 10 \%, 5 \% \text { e } 1 \% \text {. }\end{array}$} \\
\hline
\end{tabular}

\section{Conclusões}

Este estudo estimou a relação (elasticidade) entre a estrutura das tarifas de importação e a evasão de parte das importações no Brasil em 2003.

Por não ser uma variável diretamente observável, a definição utilizada de evasão foi a diferença entre o valor das exportações reportadas pelos principais parceiros comerciais do Brasil e o valor das importações registradas pela aduana brasileira, um recurso normalmente encontrado na literatura inaugurada por Bhagwatti (1964) e adotado nos estudos recentes, como os de Fisman \& Wei (2004) e Mishra et al. (2007).

A prática mais comum para a concretização da evasão é o subfaturamento do valor do produto importado, além da declaração de uma quantidade menor do bem e sua classificação em uma posição no sistema harmonizado, caso haja um ou mais similares com tarifas mais baixas.

Os resultados obtidos foram:

a) o aumento de um ponto de porcentagem na alíquota da tarifa implica uma elevação de 3,1\% no nível de sonegação. Este resultado é similar ao ob- 
tido por Fisman \& Wei $(2004)$ para a China $(3,1 \%)$ e por Javorcik \& Narciso (2008) para a Rússia (3,2\%);

b) quando os produtos são classificados em dois grupos, segundo a dificuldade na percepção da evasão por parte da aduana, um aumento de um ponto de porcentagem na tarifa proporciona uma elevação de $3,2 \%$ na evasão nos bens diferenciados e de 2,2\% nos bens homogêneos;

c) a mudança na classificação para se beneficiar de uma tarifa menor ocorre somente nos bens diferenciados.

Os dois primeiros resultados são robustos às alterações na amostra e na classificação de bens diferenciados, não ocorrendo o mesmo com os efeitos da mudança na classificação sobre a evasão.

Procedendo-se à diferenciação das tarifas em quartis, obtém-se como resultado que, nos dois primeiros, com tarifas inferiores a 9,5\%, a evasão é nula, enquanto nos intervalos a partir deste nível as elasticidades são positivas e estatisticamente crescentes, indicando a presença de um custo fixo para a prática de evasão.

\section{Apêndice A}

Tabela A.1: Lista de países escolhidos

\begin{tabular}{llll}
\hline África do Sul & Costa Rica & Islândia & Paquistão \\
Albânia & Cuba & Israel & Panamá \\
Alemanha & Croácia & Itália & Paraguai \\
Arábia Saudita & Dinamarca & Japão & Peru \\
Argélia & Emirados & Jordânia & Polônia \\
& Árabes Unidos & & \\
Argentina & Eslováquia & Líbano & Portugal \\
Armênia & Eslovênia & Lituânia & Quênia \\
Aruba & Equador & Luxemburgo & Reino Unido \\
Austrália & Espanha & Macau (China) & República Tcheca \\
Áustria & Estados Unidos & Macedônia & Romênia \\
Bangladesh & Estônia & Madagascar & Rússia \\
Bélgica & Fiji & Malaúí & El Salvador \\
Bielo-Rússia & Finlândia & Malásia & Samoa Ocidental \\
Bolívia & França & Malta & Senegal \\
Bósnia & Grécia & Marrocos & Sri Lanka \\
Herzegovina & & & \\
Bulgária & Groenlândia & México & Suécia \\
Burkina Faso & Guatemala & Moçambique & Súça \\
Canadá & Holanda & Mongólia & Tailândia \\
Chile & Honduras & Namíbia & Tunísia \\
China & Hong Kong & Nepal & Turquia \\
Chipre & (China) & & \\
Cingapura & Hungria & Nicarágua & Uganda \\
Colômbia & Irãa & Nova Caledônia & Uruguai \\
Coreia do Sul & Irlanda & (França) & \\
\hline
\end{tabular}




\section{Referências Bibliográficas}

Allingham, M. G. \& Sandmo, A. (1972), 'Income tax evasion: a theoretical analysis', Journal of Public Economics 1, 323 - 338.

Bhagwatti, J. (1964), 'On the underinvoicing of imports', Bulletin of Oxford University Institute of Economics and Statistics 26.

Fisman, R. \& Wei, S. (2004), 'Tax rates and tax evasion: evidence from missing imports in china', Journal of Political Economy 112.

Javorcik, B. S. \& Narciso, G. (2008), 'Differentiated products and evasion of import tariffs', Journal of International Economics $\mathbf{7 6 .}$

Mishra, P., Subramanian, A. \& Topalova, P. (2007), Policies, enforcement, and customs evasion: evidence from india, Technical report, Working Paper 07/60. Washington, D.C.: International Monetary Fund.

Piani, G. \& Miranda, P. (2006), Regimes especiais de importação e extarifários: o caso do Brasil, Textos para discussão, IPEA.

Ponciano, V. L. F. (2007), 'Jogo da alfândega: não cabe perdimento quando valor declarado é menor do que o real', Revista Consultor Jurídico dezembro.

Rauch, J. E. (1999), 'Networks versus markets in international trade', Journal of International Economics 48.

Sandmo, A. (2005), 'The theory of tax evasion: a retrospective view', National Tax Evasion 58, 643-663.

Siqueira, M. L. \& Ramos, F. S. (2005), 'A economia da sonegação: teorias e evidências empíricas', Revista de Economia Contemporânea 9, 555-581.

Sosa, R. B. (1993), Comentários à Lei Aduaneira - vol. III, São Paulo: Edições Aduaneiras.

Sousa, M. C. S., Tannuri-Pianto, M. E. \& Santos, C. A. S. (2008), 'Imposto de importação e evasão fiscal: uma investigação do caso brasileiro', Revista Brasileira de Economia 62(1), 77-93.

Yang, D. (2008), 'Can enforcement backfire? crime displacement in the context of customs reform in the philippines', Review of Economics and Statistics 90, $1-14$.

Yitzhaki, S. (1974), 'A note on income tax evasion: a theoretical analysis', Journal of Public Economics 3, 201-202. 